\title{
DETERMINATION OF SUSCEPTIBILITY TO INTERGRANULAR CORROSION OF STAINLESS STEELS TYPE X5CrNi18-10 IN FIELD
}

\author{
Bore V. Jegdic ${ }^{1 *}$, Biljana M. Bobic ${ }^{1}$ \\ ${ }^{1}$ University of Belgrade, Institute for Chemistry, Technology and Metallurgy \\ IHTM, Njegořeva 12, Belgrade
}

Received 18.10.2016

Accepted 17.11.2016

\begin{abstract}
In this paper, the DL EPR method (electrochemical potentiokinetic reactivation with double loop) was modified and used to study the susceptibility to intergranular corrosion and stress corrosion cracking of a stainless steel type X5CrNi18-10. The tests were performed in a special electrochemical cell, with the electrolyte in the gel form. Modified DL EPR method is characterized by simple and high accuracy measurements as well as repeatability of the test results. The indicator of susceptibility to intergranular corrosion $\left(Q_{\mathrm{r}} / Q_{\mathrm{p}}\right)_{\mathrm{GBA}}$ obtained by modified DL EPR method is in a very good agreement with the same indicator obtained by standard DL EPR method. The modified DL EPR method is quantitative and highly selective method. Small differences in the susceptibility of the stainless steel type CrNi18-10 to intergranular corrosion and stress corrosion cracking can be determined. Test results can be obtained in a short time. The cost of tests performed by modified DL EPR method is much lower than the cost of tests by conventional chemical methods. Modified DL EPR method can be applied in the field on the stainless steels constructions.

Key words: Stainless steels, intergranular corrosion, electrochemical potentiokinetic reactivation, field tests.
\end{abstract}

\section{Introduction}

During cooling or heating of stainless steels type CrNi18-10 in the temperature range from $420{ }^{\circ} \mathrm{C}$ to $820^{\circ} \mathrm{C}$, chromium rich carbides, mainly $\mathrm{M}_{23} \mathrm{C}_{6}$ can be precipitated on grain boundaries [1-3]. Their precipitation causes the depletion in chromium grain boundary areas. If the chromium content in these regions is less than the content that is necessary for maintaining the protective passive film in a given corrosive environment, the regions nearly to the grain boundaries become prone to intergranular corrosion [4-9]. This is a result of slow diffusion of chromium in the austenite in the specified temperature

\footnotetext{
* Corresponding author: Bore V. Jegdić, borejegdic@yahoo.com
} 
range, as compared to the diffusion rate of carbon. Grain boundaries areas, depleted in chromium, have a higher dissolution rate as compared to other grain areas. Susceptibility to intergranular corrosion is most common in welded joints of stainless steels, in the heataffected zone, which is parallel to the weld, or during annealing to reduce residual stresses [4-6].

Testing of susceptibility to intergranular corrosion is traditionally performed in the solution $\mathrm{H}_{2} \mathrm{SO}_{4}+\mathrm{CuSO}_{4}$ (Strauss test), in the solution of $\mathrm{H}_{2} \mathrm{SO}_{4}+\mathrm{Fe}_{2}\left(\mathrm{SO}_{4}\right)_{3}$ (Streicher test) or in the $\mathrm{HNO}_{3}$ solution (Huey test) [2]. These methods are destructive. In order to determine the structure of a stainless steel that is susceptible to intergranular corrosion electrochemical etching of the steel samples in oxalic acid can be applied (ASTM A262, Method A) [10]. After electrochemical etching the samples are observed with microscope at 500x magnification. If there are no signs of intergranular corrosion, long-term tests in boiling acid solutions are not necessary. If there are signs of intergranular corrosion at grain boundaries, the samples are tested in the appropriate acid solutions [10]. Testing time is relatively long, and depending on the test method can be up to 10 days.

Testing time can be significantly reduced if DL EPR method is applied, according to the standard ISO 12732 [11]. Testing of susceptibility to intergranular corrosion by DL EPR method lasts about $20 \mathrm{~min}$. The test is conducted in a solution of sulfuric acid and potassium thiocyanate. Potassium thiocyanate is added as an agent that causes activation and dissolution of the chromium depleted grain boundary areas. The electrode potential of a stainless steel sample, which is in solution, is gradually shifting from the corrosion potential $E_{\text {corr }}$ in the positive potential region to the passivation, and then in the reverse direction to the $E_{\text {corr }}$. If the stainless steel is susceptible to intergranular corrosion activation of the grain boundaries takes place in the reverse part of the loop. The ratio of the charge amount that is spent during reactivation (ie. during dissolution of the grain boundary areas) and the charge amount consumed during activation (ie. during dissolution of grains and grain boundaries), is an indicator of the susceptibility to intergranular corrosion. Also, the ratio of the current peak value in the reverse part of the loop (reactivation) and the passivation current peak value in the activation part of the loop can represent a measure of the susceptibility to intergranular corrosion. DL EPR method can be applied with certain modifications to test susceptibility to intergranular corrosion of other types of stainless steels [12-15].

Stainless steel X5CrNi18-10 belongs to a class of stainless steels CrNi18-10, which have a wide application in various industries. One of the main disadvantages of these steels is the appearance of intergranular corrosion in the heat affected zone of the welded joint, in operating conditions. The aim of this work is to modify the DL EPR method and to apply the modified method for testing susceptibility to intergranular corrosion and stress corrosion cracking of stainless steels type CrNi18-10. The modified DL EPR method can also be applied in the field, on stainless steels structures. Testing of susceptibility to intergranular corrosion of these steel by standard DL EPR method is carried out in laboratory conditions. 


\section{Experimental}

Material

The susceptibility testing to intergranular corrosion using the modified DL EPR method is carried out on samples of the stainless steel X5CrNi18-10. The chemical composition of the stainless steel $\mathrm{X} 5 \mathrm{CrNi18}-10$ is given in Table 1.

Table 1. The chemical composition of the stainless steel X5CrNi18-10

\begin{tabular}{llllllll}
\hline Element & $\mathrm{C}$ & $\mathrm{Si}$ & $\mathrm{Mn}$ & $\mathrm{Cr}$ & $\mathrm{Ni}$ & $\mathrm{Mo}$ & $\mathrm{N}$ \\
\hline mass. \% & 0.04 & 0.34 & 1.20 & 18.8 & 9.5 & 0.22 & 0.05 \\
\hline
\end{tabular}

Testing was performed on the samples without heat treatment, ie. on the nonsensitized samples, as well as on the sensitized samples. Sensitization heat treatment was carried out at $630{ }^{\circ} \mathrm{C}$ for $90 \mathrm{~min}$, in accordance with the position of the peak in the Ccurve $[6,7]$. In the case of this stainless steel the peak at the C-curve for chromium carbides precipitation is located at $\sim 630^{\circ} \mathrm{C}$. The stainless steel samples have dimensions: $25 \mathrm{~mm}$ x $50 \mathrm{~mm} \times 6 \mathrm{~mm}$. Before testing, the samples were grounded with emery paper $\mathrm{P} 600$, and then with progressively finer paper up to emery paper P1500. After that, the samples were polished with an aqueous suspension of $\mathrm{Al}_{2} \mathrm{O}_{3}$ with $5 \mu \mathrm{m}$ grain size. The samples were degreased with ethanol, washed with distilled water and air-dried.

\section{Test methods}

Testing by the modified DL EPR method was performed in the electrolyte in the gel form. The electrolyte contains about 90 mass. $\%$ of the standard solution $\left(0.5 \mathrm{~mol} \mathrm{dm}^{-}\right.$ ${ }^{3} \mathrm{H}_{2} \mathrm{SO}_{4}+0.01 \mathrm{~mol} \mathrm{dm}^{-3} \mathrm{KSCN}$ ) and 10 mass.\% of an inert supstance in order to convert the solution in the gel form. $\mathrm{SiO}_{2}$ powder of nanometer granulation was used for this purpose. The electrolyte in a gel form is prepared from the standard solution in which $\mathrm{SiO}_{2}$ powder was added in small portions, with vigorous stirring by a mechanical stirrer. The electrolyte in a gel form is further homogenized by a treatment in an ultrasonic bath.

In addition to testing the susceptibility to intergranular corrosion by the modified DL EPR method, the tests were also carried out by the standard DL EPR method [11] for the purpose of comparison. The tests by the standard DL EPR method were performed in a standard electrochemical cell, in the standard solution $\left(0.5 \mathrm{~mol} \mathrm{dm}^{-3} \mathrm{H}_{2} \mathrm{SO}_{4}+0.01 \mathrm{~mol}\right.$ $\mathrm{dm}^{-3} \mathrm{KSCN}$ ), without the addition of $\mathrm{SiO}_{2}$.

Testings by the modified DL EPR method are carried out in a special electrochemical cell made of Teflon, with a small volume $\left(\sim 35 \mathrm{~cm}^{3}\right)$. The cell can be used for testings in the field, on the stainless steels constructions. The reference electrode is a saturated calomel electrode (SCE) with a double mantle. Platinum wire wrapped around the outer cover of the SCE is the counter electrode. The working electrode is a test sample of stainless steel X5CrNi18-10 (non-sensitized or sensitized). The hole in the bottom of the electrochemical cell through which the sample is in electrical contact with the electrolyte in a gel form, has a surface area $\sim 0.2 \mathrm{~cm}^{2}$. The electrochemical cell was carefully filled with the gel electrolyte. The electrochemical cell and its components are shown in Figure 1. 


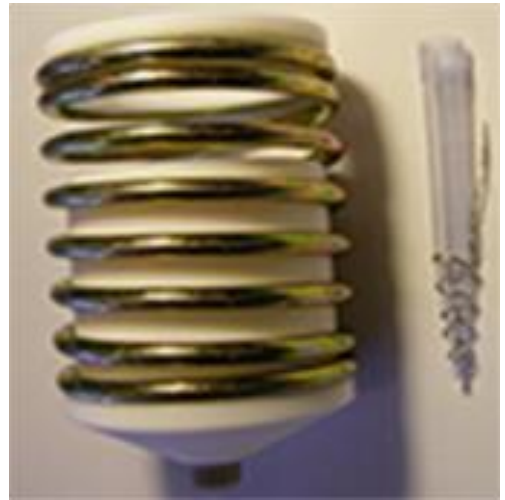

a)

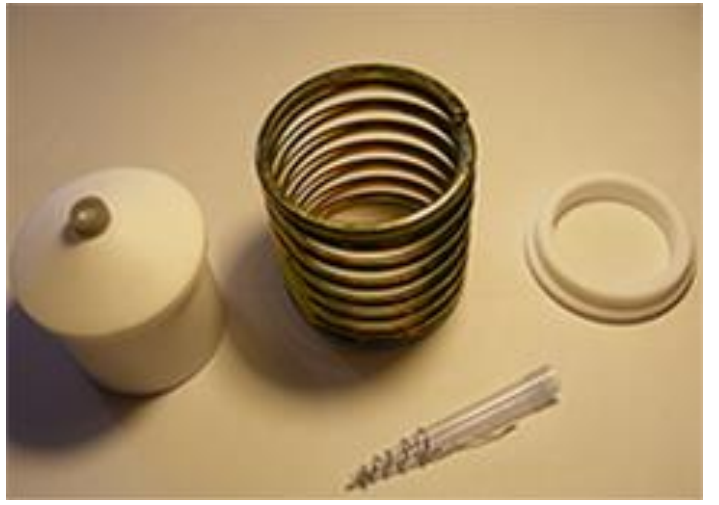

b)

Fig. 1. a) the electrochemical cell for testing susceptibility to intergranular corrosion by the modified DL EPR method and b) cell components.

In the test solution (standard electrolyte or gel electrolyte), relatively stable $E_{\text {corr }}$ on the stainless steel sample was established in the potential range from $-350 \mathrm{mV}$ to -450 $\mathrm{mV}$. The sample was held for $5 \mathrm{~min}$ at $E_{\text {corr }}$, and then the potential of the sample was shifted in the positive direction to the sample passivation $(+300 \mathrm{mV})$, at $1.67 \mathrm{mV} \mathrm{s}^{-1}$ scan rate. Immediately after reaching the passivation potential $(+300 \mathrm{mV})$ the polarisation direction was changed and the potential of the sample was returned to the $E_{\text {corr. }}$ If the stainless steel is susceptible to intergranular corrosion, the activation of the grain boundaries takes place in the reverse part of the loop. The ratio of the charge amount that was spent during the reactivation (i.e. during the dissolution of the grain boundary areas, $Q_{\mathrm{r}}$ ) and the charge amount consumed during the activation (ie. during the dissolution of grains and grain boundaries, $Q_{\mathrm{p}}$ ) is an indicator of tendency to intergranular corrosion $\left(Q_{\mathrm{r}} / Q_{\mathrm{p}}\right)_{\mathrm{GBA}}$ :

$$
\left(\frac{Q_{r}}{Q_{p}}\right)_{G B A}=\frac{Q_{r}}{Q_{p} \cdot\left(10^{-3} \cdot \sqrt{2^{G+5}}\right)}
$$

$\mathrm{G}$ is grain size according to standard ISO 643 [16].

The grain size is determined by chemical etching of the metallographically prepared stainless steel sample surface, according to ISO 21610 [17]. The grain size of the non-sensitized and sensitized stainless steel sample is $18-20 \mu \mathrm{m}(\sim \mathrm{G} 9)$.

By applying a scanning electron microscope JEOL JSM - 5800 the sample surface was analyzed after testing the susceptibility to intergranular corrosion.

\section{Results and disscusion}

The results of testing using the modified DL EPR method are shown in Figures 2a and $\mathrm{b}$. It can be seen that the value of maximum reactivation current $I_{\mathrm{r}}$ and reactivation charge $Q_{\mathrm{r}}$ is significantly lower for the non-sensitized sample than for the sensitized sample. The results from Figure $2 \mathrm{a}$ and $\mathrm{b}$ are shown together in Figure $2 \mathrm{c}$ in the purpose of comparison. 

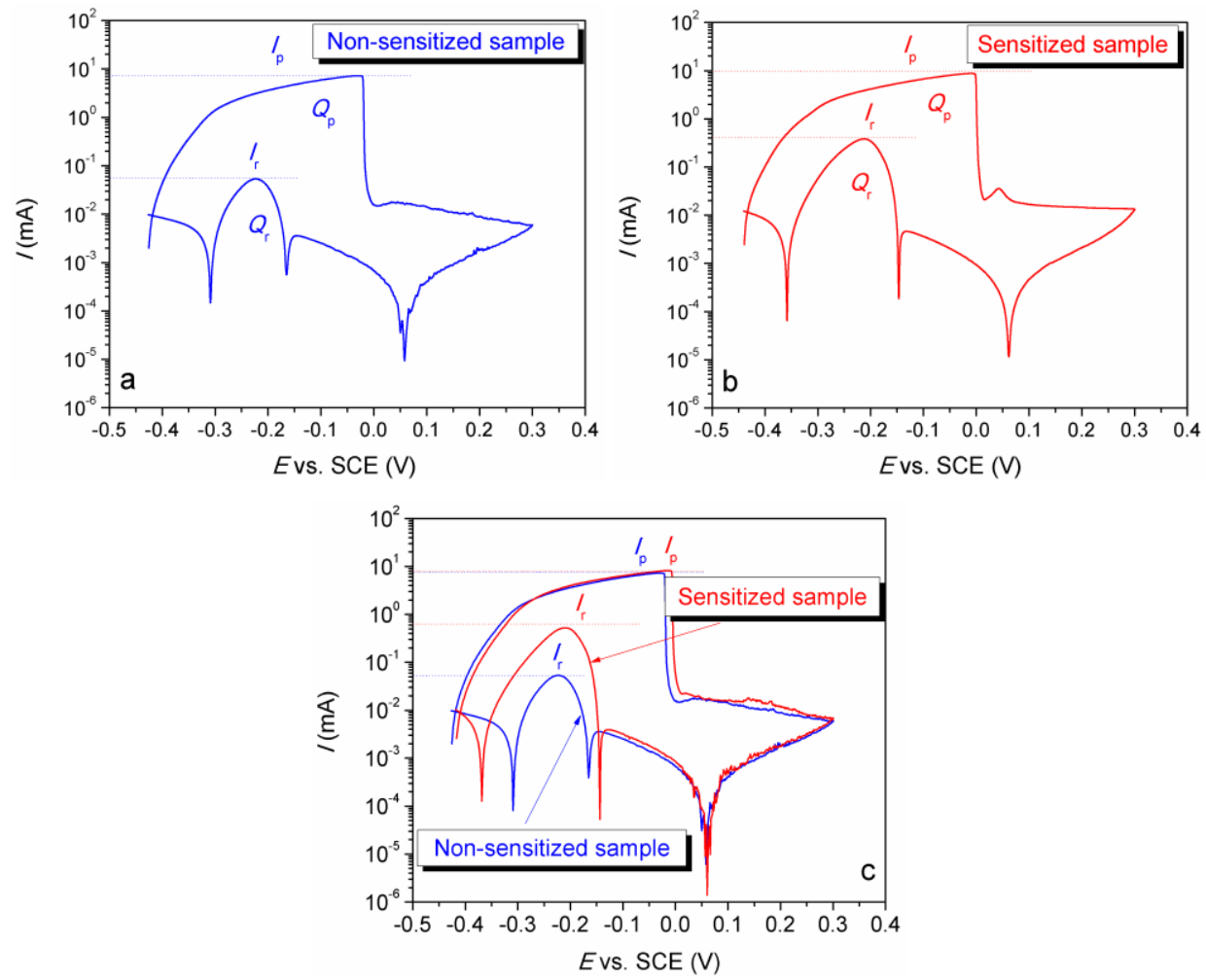

Fig. 2. Results of testing susceptibility to intergranular corrosion by the modified DL EPR method: a) non-sensitized sample, b) sensitized sample and c) joined results.

Quantitative indicators of the susceptibility to intergranular corrosion, obtained by the modified DL EPR method for the stainless steel X5CrNi18-10, are presented in Table 2.

Table 2. Quantitative indicators of susceptibility to intergranular corrosion obtained by the modified DL EPR method

\begin{tabular}{lcccccc}
\hline Sample & $\begin{array}{c}E_{\text {corr }} \\
(\mathrm{mV})\end{array}$ & $\begin{array}{c}I_{\mathrm{r}} \\
(\mu \mathrm{A})\end{array}$ & $\begin{array}{c}I_{\mathrm{p}} \\
(\mu \mathrm{A})\end{array}$ & $\begin{array}{c}Q_{\mathrm{r}} \\
(\mathrm{mC})\end{array}$ & $\begin{array}{c}Q_{\mathrm{p}} \\
(\mathrm{mC})\end{array}$ & $\begin{array}{c}\left(Q_{\mathrm{r}} / Q_{\mathrm{p}}\right)_{\mathrm{GBA}} \\
(\%)\end{array}$ \\
\hline Non-sensitized & -425 & 53.6 & 7273 & 2.504 & 792.4 & 2.47 \\
Sensitized & -427 & 450.9 & 7426.5 & 23.58 & 809.9 & 22.74 \\
\hline
\end{tabular}

The values of the quantitative indicator $\left(Q_{\mathrm{r}} / Q_{\mathrm{p}}\right)_{\mathrm{GBA}}$ (Table 2$)$ were calculated using the equation 1. Very low value of $\left(Q_{\mathrm{r}} / Q_{\mathrm{p}}\right)_{\mathrm{GBA}}$ for the non-sensitized sample indicates that the stainless steel $\mathrm{X} 5 \mathrm{CrNi18-10,} \mathrm{which} \mathrm{was} \mathrm{not} \mathrm{heat-treated,} \mathrm{is} \mathrm{not} \mathrm{susceptible} \mathrm{to}$ intergranular corrosion. Significantly higher value of $\left(Q_{\mathrm{r}} / Q_{\mathrm{p}}\right)_{\mathrm{GBA}}$ for the sensitized sample indicates that the stainless steel is susceptible to intergranular corrosion after sensitization 
heat treatment. The value of indicator $\left(Q_{\mathrm{r}} / Q_{\mathrm{p}}\right)_{\mathrm{GBA}}$ is $\sim 9$ times greater for the sensitized sample than for the non-sensitized sample.

During sensitization heat treatment of the stainless steel $\mathrm{X} 5 \mathrm{CrNi} 18-10$ the precipitation of chromium-rich $\mathrm{M}_{23} \mathrm{C}_{6}$ carbides occur as well as depletion in chromium at grain boundary areas. According to the standard ASTM G108 [18] width of the chromium depleted areas, on each side of the grain boundary is $\sim 0.5 \mu \mathrm{m}$. Total surface area of the sensitized grain boundary areas on the sample surface $S_{\mathrm{GBA}}$ can be determined using the following equation, in accordance with ISO 12732 [11]:

$$
\mathrm{S}_{\mathrm{GBA}}=\mathrm{A}_{\mathrm{S}} \cdot\left(10^{-3} \cdot \sqrt{2^{\mathrm{G}+5}}\right)
$$

$A_{\mathrm{s}}$ is sample surface and $\mathrm{G}$ is grain size according to standard ISO 643 [16].

The actual formula of $\mathrm{M}_{23} \mathrm{C}_{6}$ carbide is $(\mathrm{Cr}, \mathrm{Fe})_{23} \mathrm{C}_{6}$, because a certain number of $\mathrm{Cr}$ atoms is replaced by $\mathrm{Fe}$ atoms in chromium-carbide [1-5]. The stainless steel which is susceptible to intergranular corrosion is also susceptible to stress corrosion cracking. The modified DL EPR method can also be applied for testing susceptibility of stainless steel type CrNi18-10 to stress corrosion cracking in the field, at steel constructions [11].

Testing results of susceptibility to intergranular corrosion for the stainless steel X5CrNi18-10 obtained using the standard DL EPR method (in a standard electrochemical cell, with a standard liquid electrolyte) are shown in Figures $3 \mathrm{a}$ and $\mathrm{b}$.
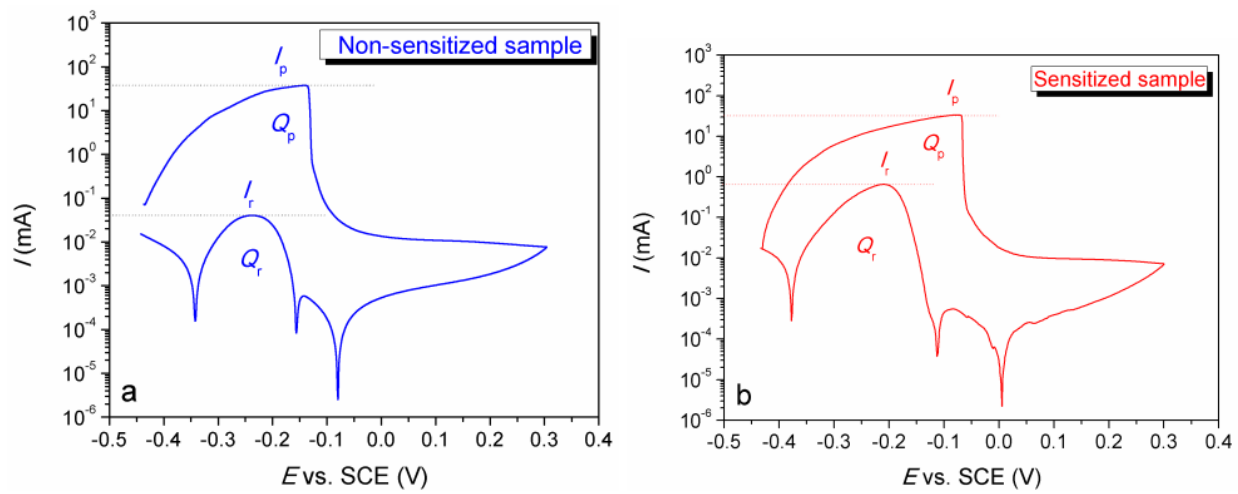

Fig. 3. Results of testing susceptibility to intergranular corrosion by the standard DL EPR method: a) non-sensitized sample and b) sensitized sample.

It can be seen in Figure 3 that the values of maximum reactivation current $I_{\mathrm{r}}$ and reactivation charge $Q_{\mathrm{r}}$ are significantly lower for the non-sensitized sample than for the sensitized sample, similarly to the results obtained by using the modified DL EPR method. The indicator of susceptibility to intergranular corrosion $\left(Q_{\mathrm{r}} / Q_{\mathrm{p}}\right)_{\mathrm{GBA}}$ obtained by the standard DL EPR method is 12 times higher for the sensitized sample than for the non-sensitized sample.

Repeatability of the modified DL EPR method was verified by 3 repeated tests of susceptibility to intergranular corrosion, on the sensitized and non-sensitized samples. The tests were carried out without replacing the electrolyte in a gel form. Obtained results are shown in Figures $4 \mathrm{a}$ and $\mathrm{b}$, while the corresponding indicators of susceptibility to intergranular corrosion are given in Table 3. 

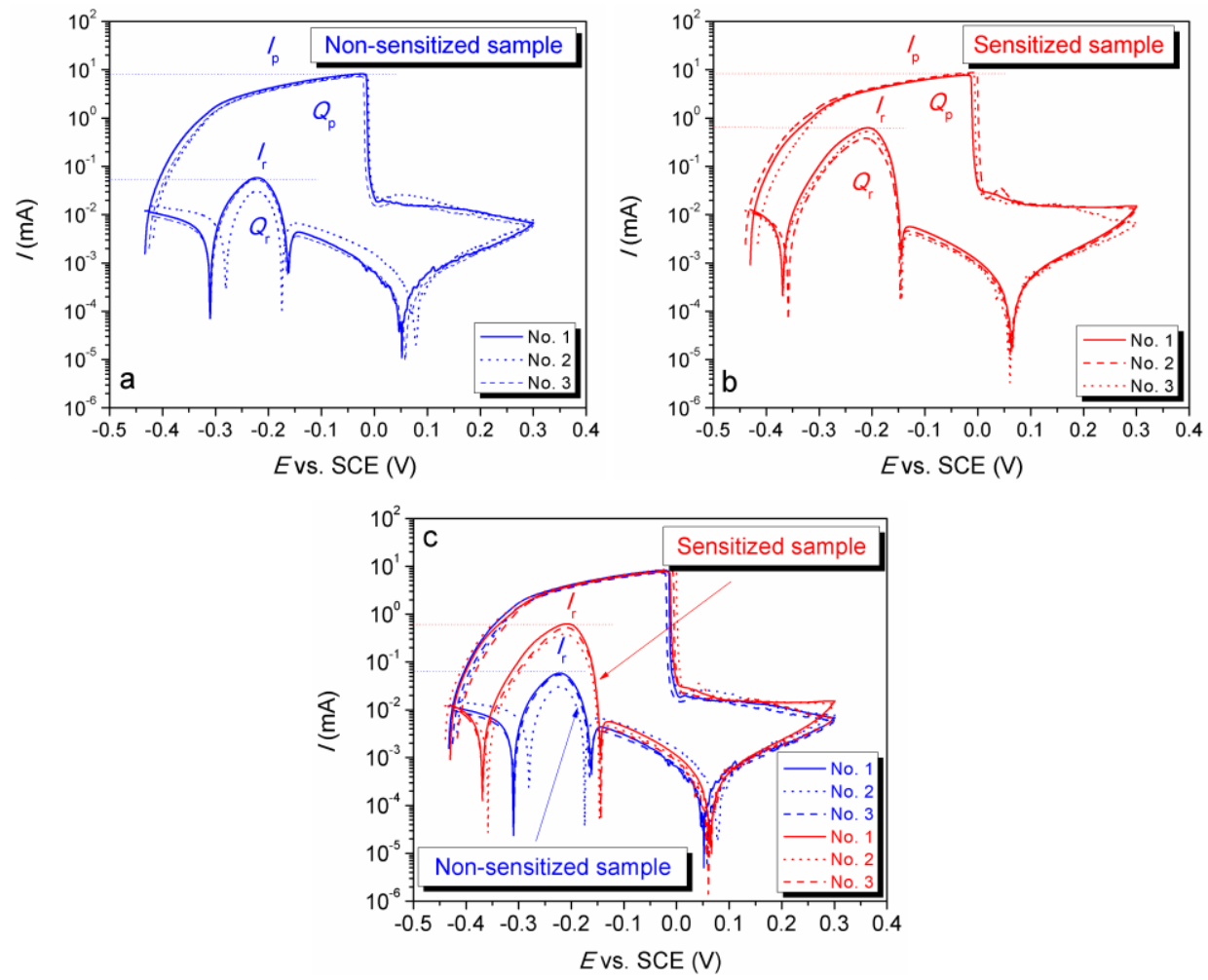

Fig. 4. Repeatability of testing susceptibility to intergranular corrosion by the modified DL EPR method: a) non-sensitized sample, b) sensitized sample and c) joined results (test is repeated 3 times).

Table 3. Repeatability of testing results obtained by the modified DL EPR method

\begin{tabular}{lccccccc}
\hline Sample & $\begin{array}{c}\text { Exp. } \\
\text { No. }\end{array}$ & $\begin{array}{c}E_{\text {corr }} \\
(\mathrm{mV})\end{array}$ & $\begin{array}{c}I_{\mathrm{r}} \\
(\mu \mathrm{A})\end{array}$ & $\begin{array}{c}I_{\mathrm{p}} \\
(\mu \mathrm{A})\end{array}$ & $\begin{array}{c}Q_{\mathrm{r}} \\
(\mathrm{mC})\end{array}$ & $\begin{array}{c}Q_{\mathrm{p}} \\
(\mathrm{mC})\end{array}$ & $\begin{array}{c}\left(Q_{\mathrm{r}} / Q_{\mathrm{p}}\right)_{\mathrm{GBA}} \\
(\%)\end{array}$ \\
\hline Non- & 1 & -438 & 76.9 & 9301 & 4.027 & 1132 & 2.78 \\
sensitized & 2 & -433 & 58.2 & 8227 & 2.841 & 931.8 & 2.38 \\
& 3 & -417 & 30.5 & 7856 & 1.382 & 867.5 & 1.25 \\
& 4 & -425 & 53.6 & 7273 & 2.504 & 792.4 & 2.47 \\
Sensitized & 1 & -430 & 629.4 & 7705 & 33.64 & 877.6 & 29.95 \\
& 2 & -427 & 450.9 & 7427 & 23.58 & 809.9 & 22.74 \\
& 3 & -439 & 382.2 & 8764 & 18.80 & 1023.4 & 14.35 \\
& 4 & -416 & 523.6 & 8168 & 26.29 & 915.0 & 22.45 \\
\hline
\end{tabular}

It can be seen that the repeatability of the test results is very good. The average value of the indicator $\left(Q_{\mathrm{r}} / Q_{\mathrm{p}}\right)_{\mathrm{GBA}}$ is $2.22 \pm 0.58$ for the non-sensitized sample, while the average value of the $\left(Q_{\mathrm{r}} / Q_{\mathrm{p}}\right)_{\mathrm{GBA}}$ is $22.37 \pm 5.52$ for the sensitized sample. It can be seen 
that the average value of the indicator $\left(Q_{\mathrm{r}} / Q_{\mathrm{p}}\right)_{\mathrm{GBA}}$ is $\sim 10$ times higher for the sensitized sample than for the non-sensitized sample.

The modified DL EPR method allows a greater number of testing susceptibility to intergranular corrosion, for stainless steels type CrNi18-10, in the field, at steel constructions, as well as in welded joints of the stainless steels. At least 8 tests of susceptibility to intergranular corrosion can be performed without replacing the electrolyte in a gel form. Tests for susceptibility to intergranular corrosion by applying the modified DL EPR method are non-destructive.

The typical SEM micrographs of the stainless steel X5CrNi18-10 surface after testing the susceptibility to intergranular corrosion are shown in Figure 5. There was a significant dissolution og grain boundary areas in the case of the sensitized steel sample, while the dissolution is negligible in the case of the non-sensitized steel sample.


Fig. 5. SEM micrographs of the stainless steel X5CrNi18-10 after testing susceptibility to intergranular corrosion: a) non-sensitized sample and b) sensitized sample.

\section{Conclusion}

In this work the DL EPR method has been modified and applied for testing the susceptibility to intergranular corrosion of the stainless steel X5CrNi18-10. The tests were performed in a special electrochemical cell with the electrolyte in a gel form. This electrolyte is formed by adding $\mathrm{SiO}_{2}$ powder with nano-size particles in the standard electrolyte for testing intergranular corrosion. At least 8 tests can be performed without replacement the electrolyte in a gel form.

Testing of susceptibility to intergranular corrosion using the modified DL EPR method is characterized by simplicity, high precision and very good repeatability of test results. The values of $\left(Q_{\mathrm{r}} / Q_{\mathrm{p}}\right)_{\mathrm{GBA}}$ indicator obtained by the modified DL EPR method are in very good agreement with the values of the same indicator obtained by the standard DL EPR method.

The modified DL EPR method is quantitative and very selective method. By using this method small differences in the susceptibility to intergranular corrosion and stress corrosion cracking can be determined for the stainless steels type CrNi18-10. Test results are obtained in a short time. The modified DL EPR method is non-destructive method and can be applied in the field. The cost of tests performed by the modified DL EPR method is much lower than the cost of test conducted by conventional chemical testing methods. 


\section{Acknowledgement}

This work was co-financed from the Ministry of Education, Science and Technological Development of the Republic of Serbia through projects TR 34028 and TR 35021.

\section{Literatura}

[1] K.H. Lo, C.H. Shek, J.K.L. Lai: Mater Sci Eng, R 65 (2009) 39-104.

[2] M.A. Streicher (Revised by J. F. Grubb), Austenitic and Feritic Stainless Steels, Uhlig's Corrosion Handbook, Third Edition, Edited by R.W. Revie, John Wiley \& Sons, New Jersey, 2011, 657-693.

[3] K. Kaneko, T. Fukunaga, K. Yamada, N. Nakada, M. Kikuchi, Z. Saghi, J.S. Barnard and P.A. Midgley: Scr Mater, 65 (2011) 509-512.

[4] D.L. Engelberg, Intergranular Corrosion, in Shreir's Corrosion, Volume Two, Fourth Edition, Academic Press, Oxford, 2010, 810-827.

[5] V. Čihal, Mežkristallitnaja korrozija neržavejušćih stalej. Perevod s češskogo. Himija, Leningradskoe otdelenie, 1969.

[6] Corrosion of Austenitic Stainless Steel Weldments in Corrosion of Weldments, J.R. Davis, editor, ASM International, Materials Park, Ohio, 2006, 43-75.

[7] Corrosion of Stainless Steel Weldments, Corrosion: Fundamentals, Testing, and Protection, Vol 13A, ASM Handbook, ASM International, Materials Park, Ohio, 2003, 301-316.

[8] Sindo Kou, Corrosion-Resistant Materials: Stainless Steels inWelding Metallurgy, John Wilry \& Sons, New Jersey, 2003.

[9] Basic Understanding of Weld Corrosion in Corrosion of Weldments, J.R. Davis, Editor, ASM International, Materials Park, Ohio, 2006, 1-12.

[10] Standard Practices for Detecting Susceptibility to Intergranular Attack in Austenitic Stainless Steels - ASTM A262.

[11] Electrochemical potentiokinetic reactivation measurement using the double loop method (based on Čihal's method) - ISO 12732.

[12] Bore V. Jegdić, Biljana M. Bobić, Behar Alić: Weld Welded Struct, 61 (2016) 1318.

[13] B.V. Jegdić, A.B. Alil, Z.R. Milutinović, Z.D. Odanović, B.R. Gligorijević, B.T. Katavić, Hem Ind, 65 (2) (2011) 179-186.

[14] B. Bobić i B. Jegdić: Weld Welded Struct, 50 (2005) 217-223.

[15] B. Bobić i B. Jegdić, Weld Welded Struct, 51 (2006) 77-85.

[16] Micrographic determination of the apparent grain size-ISO 643.

[17] Accelerated corrosion test for intergranular corrosion susceptibility of austenitic stainless steels - ISO 21610.

[18] Standard Test Method for Electrochemical Reactivation (EPR) for Detecting Sensitization of AISI Type 304 and 304L Stainless Steels - ASTM G108. 